Gelanggang Olahraga: Jurnal Pendidikan Jasmani dan Olahraga

Volume 3, Nomor 1, Juli-Desember 2019

e-ISSN : $2597-6567$

p-ISSN : 2614-607X

DOI : https://doi.org/10.31539/jpjo.v3i1.829

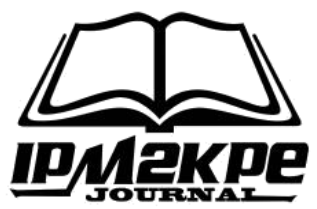

\title{
KONTRIBUSI KEKUATAN OTOT LENGAN TERHADAP KETERAMPILANSMASH DALAM PERMAINAN BOLA VOLI
}

\author{
Supriyanto $^{1}$, Martiani $^{2}$ \\ Universitas Dehasen Bengkulu $^{1,2}$ \\ Supriyanto@unived.ac.id ${ }^{1}$
}

\begin{abstract}
ABSTRAK
Penelitian ini bertujuan untuk mengetahui kontribusi kekuatan otot lengan terhadap keterampilan smash dalam permainan bolavoli pada ekstrakurikuler di SMA Negeri 2 Seluma. Penelitian ini menggunakan metode korelasi yaitu teknik analisis korelasi dengan statistik product moment, penelitian ini menggunakan sampel 24 siswa yang diambil dengan teknik purposive sampling. Siswa memiliki tingkat kekuatan otot lengan pada kategori cukup yaitu dengan rata-rata 13,46 dantingkat keterampilan smashmemiliki tingkat keterampilan smash pada kategori baik yaitu dengan rata-rata 18,33 , $t$-hitung $\geq \mathrm{t}$-tabel yaitu $7,62 \geq 2,07$ pada taraf signifikansi $\alpha=0,05(0,5 \%)$. Simpulan, ada hubungan yang signifikan antara kekuatan otot lengan dengan kemampuan smash.
\end{abstract}

Kata Kunci :Kekuatan Otot Lengan, Keterampilan Smash

\section{ABSTRACT}

This study aims to determine the contribution of arm muscle strength to smash skills in the game of volleyball on extracurricular activities at SMA Negeri 2 Seluma. This study uses the correlation method, which is a correlation analysis technique with product moment statistics, this study uses a sample of 24 students taken by purposive sampling technique. Students have the level of arm muscle strength in the adequate category with an average of 13.46 and the level of smash skills have a level of smash skills in the good category with an average of 18.33, $t$ count $\geq t$-table is $7.62 \geq 2.07$ at the significance level $\alpha=0.05(0.5 \%)$. Thus it can be concluded that there is a significant relationship between arm muscle strength and smash ability

Keywords: Arm Muscle Strength, Smash Skills

\section{PENDAHULUAN}

Bolavoli merupakan cabang olahraga permainan yang telah dikenal masyarakat mulai dari usia anak-anak sampai dewasa, baik laki-laki maupun perempuan. Bolavoli adalah salah satu cabang olahraga yang tercantum dalam kurikulum jenjang pendidikan SMA. Pada jenjang pendidikan SMA materi permainan bolavoli diajarkan di kelas X, kelas XI, dan kelas XII, sehingga waktu yang tersedia untuk pembelajaran materi permainan bolavoli pada jenjang 
pendidikan SMA cukup banyak. Teknik dalam permainan bolavoli merupakan faktor yang sangat penting.

Permainan bolavoli terdiri atas beberapa teknik yaitu servis, passing bawah, passing atas, smash, dan blocking. Kelima teknik di atas, smash memegang peranan yang sangat penting karena tanpa smash yang benar maka dalam permainan bolavoli tersebut tidak akan berjalan dengan baik dan seru. Smash merupakan salah satu bentuk serangan dalam permainan bolavoli yang paling memikat para pemain dan juga selalu mengundang kekaguman para penonton. Di dalam suatu permainan bolavoli smash juga merupakan suatu teknik untuk mempermudah mendapatkan nilai atau angka.

Smash mempunyai ciri-ciri menukik, tajam, dan cepat. Untuk melakukan smash dengan baik perlu memperhatikan faktor-faktor berikut: awalan, tolakan, pukulan, dan pendaratan. Sedangkan menurut pendapat M. Mariyanto smash adalah suatu pukulan yang kuat dimana tangan kontak dengan bola secara penuh pada bagian atas, sehingga jalannya bola terjal dengan kecepatan yang tinggi, apabila pukulan bola lebih tinggi berada di atas net, maka bola dapat dipukul tajam ke bawah.

Hasil penelitian Sovensi (2018) menyatakan terdapat hubungan yang signifikan antara koordinasi mata tangan dan ekstensi togok secara bersama-sama dengan ketepatan smash. Kemudian hasil penelitian Supriyanto (2018) menyatakan pemain yang memiliki kecepatan reaksi tinggi lebih efisien dilatih dengan metode latihan beban, sedangkan pemain yang memiliki kecepatan reaksi rendah lebih efisien dilatih dengan metode latihan plyometric. Sedangkan menurut Wijatmiko (2012) hasil belajar passing bawah meningkat setelah dilakukan tindakan yang berupa pembelajaran passing bawah dengan menggunakan bola dari siklus 1 sampai siklus 2 .

Pada saat melakukan teknik smash tentunya membutuhkan kekuatan otot lengan. Kekuatan otot lengan dapat bekerja secara maksimal apabila tenaga yang dikeluarkan dapat dikontrol dengan baik. Berdasarkan paparan tersebut bahwa kekuatan otot lengan mempunyai kontribusi atau sumbangan yang cukup dominan dalam kemampuan smash. Secara teoritis, faktor penentu kemampuan tersebut dapat dipertanggungjawabkan kebenarannya, namun perlu dibuktikan secara empiris bagaimana sumbangan faktor tersebut terhadap kemampuan smash.

\section{KAJIAN TEORI}

Menurut Ahmadi (2007) permainan bolavoli merupakan suatu permainan yang kompleks yang tidak mudah dilakukan oleh setiap orang. Oleh karena itu permainan bolavoli dibutuhkan koordinasi gerak yang benar-benar bisa diandalkan untuk melakukan semua gerakan yang ada dalam permainan bolavoli. Menurut Vierra dan Ferguson (2004) prinsip dasar bermain bolavoli yaitu memukul bola ke arah bidang lapangan musuh sedemikian rupa agar dapat mengembalikanbola.

Berdasarkan beberapa pendapat di atas dapat disimpulkan bahwa, hakekat permainan bolavoli adalah suatu permainan yang bertujuan untuk hiburan dan peningkatan prestasi yang menggunakan prinsip dasar memantulkan bola bergantian dengan teman seregu maksimal sebanyak tiga kali dan setelah itu harus segera diseberangkan melewati net menuju daerah lawan. 
Kekuatan adalah komponen kondisi fisik seseorang tentang kemampuannya dalam mempergunakan otot untuk menerima beban sewaktu bekerja maksimal (Ahmadi, 2007). Sedangkan menurut Nurhasan (2005) kekuatan adalah kemampuan sekelompok otot dalam menahan beban secara maksimal.Jadi kekuatan otot adalah kemampuan kondisi fisik seseorang dalam menahan beban sewaktu bekerja secara maksimal.

Menurut Irianto (2004) kekuatan otot adalah kemampuan otot melawan beban dalam satu usaha. Menurut Kravitz (2001) kekuatan otot adalah kemampuan otot yang menggunakan tenaga maksimal, untuk mengangkat beban.Otot yang kuat dapat melindungi persendian yang dikelilinginya dan mengurangi kemungkinan terjadinya cidera karena aktivitas fisik. Menurut Harsono (1988) kekuatan otot lengan adalah kemampuan dari otot lengan untuk membangkitkan tegangan dengan suatu tahanan dan mengangkat beban.

Lutan (2000) mengemukakan bahwa kekuatan merupakan komponen yang sangat penting untuk meningkatkan kondisi fisik seseorang secara keseluruhan.Beliau juga menyebutkan bahwa 13 kekuatan otot merupakan kemampuan badan dalam menggunakan daya.Kekuatan merupakan daya penggerak setiap aktivitas fisik dan juga memegang peranan penting dalam melindungi atlet dari kemungkinan cidera.Kekuatan juga bisa menjadikan atlet bisa lari lebih cepat, melempar lebih jauh, mengangkat lebih berat, menarik, mendorong, memukul, menendang lebih keras dan lain-lain.

\section{METODE PENELITIAN}

\section{Kekuatan Otot Lengan ( $\mathrm{X}$ )}

Kekuatan otot lengan diukur melalui tes push-up.Tes push-up dilakukan sebanyak mungkin tanpa diselingi istirahat. Menurut Widiastuti (2017) pelaksanaan tes push-up meliputi:

1. Posisi Awal : Testee menelungkup dan menempatkan telapak tangan di lantai di bawah dada peserta tes. Kedua tangan peserta tes terletak di lantai di bawah kedua bahunya, siku dipertahankan atau dikunci dalam keadaan lengan diluruskan. Seluruh tubuh lurus, tidak ada bagian tubuh yang menyentuh lantai kecuali kedua tangan dan tumitnya. Kedua kaki diregangkan selebarbahu.

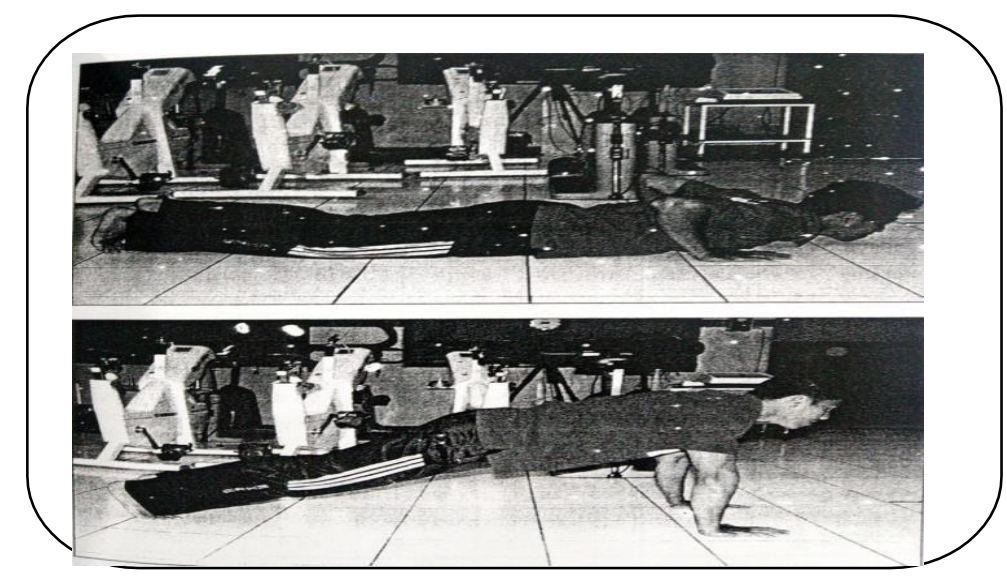

Gambar 1 Tes Push-Up 
2. Pelaksanaan : Peserta tes membengkokkan lengannya, badan diturunkan sampai dadanya dapat menyentuh tangan penghitung dan dorong kembali ke posisi awal. Tubuh harus tetap dipertahankan dengan lurus sepanjang melakukan gerakan. Testee melakukan tes sebanyak mungkin tanpa harusberhenti.

3. Penilaian : Nilai yang diberikan didasarkan atas jumlah pengulangan yang dilakukan denganbenar.

\section{Keterampilan Smash ( Y)}

Keterampilan smash diukur melalui tes melakukan smash. Menurut Nurhasan (2005) petunjuk pelaksanaan smash dilakukan sebaik-baiknya dengan teknikyang benar sebanyak 6 kali data atau point di hitung ketika bola masuk dan mengenai area yangdiberikan nomor tetapi ketika bola selama 6 kali pukulan tidak atau hanya mengenai net data tidak dihitung. Penilaian (skor) dilakukan berdasarkan hasil smash yang jatuh ke daerah dengar skor yang tinggi. Adapun penilaian smash dapat dilihat pada gambar berikut ini:

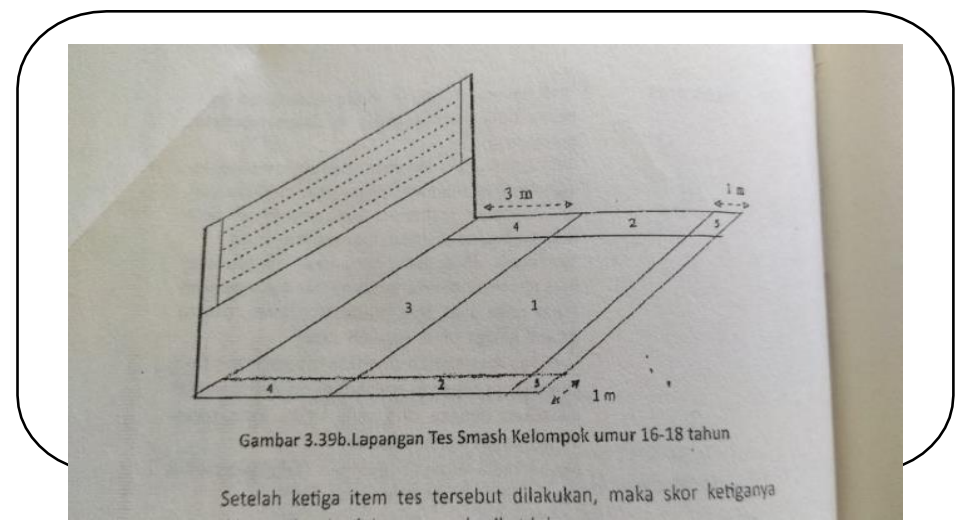

Gambar 2 Lapangan Tes Smash

\section{HASIL PENELITIAN}

Data merupakan hasil tes dan pengukuran didalam penelitian ini tes yang digunakan adalah tes kekuatan otot lengan (Push Up) dan tes smash dalam permainan Bola Voli. Berdasarkan dari hasil lengan (Push Up) dan tes smash dalam permainan Bola Voli pada siswa ekstrakurikuler, maka diperoleh nilai ratarata, nilai maksimal dan nilai minimal yang diperoleh Siswa Ekstrakurikuler pada masing-masing tes yang dilakukan. Untuk lebih jelasnya dapat diperhatikan pada tabel dibawah ini:

Tabel1

Deskripsi Data

\begin{tabular}{lccccc}
\hline \multicolumn{1}{c}{ Nama Tes } & $\begin{array}{c}\text { Jumlah } \\
\text { Hasil } \\
\text { Tes }\end{array}$ & $\begin{array}{c}\text { Nilai } \\
\text { Tertinggi }\end{array}$ & $\begin{array}{c}\text { Nilai } \\
\text { Terendah }\end{array}$ & $\begin{array}{c}\text { Nilai } \\
\text { Rata- } \\
\text { rata }\end{array}$ & $\begin{array}{c}\text { Norma } \\
\text { Penilaian }\end{array}$ \\
\hline Push Up & 323 & 21 & 28 & 13,46 & Cukup \\
\hline $\begin{array}{l}\text { Keterampilan } \\
\text { Smash }\end{array}$ & 440 & 4 & 12 & 18,33 & Baik \\
\hline
\end{tabular}


Sebelum melaksanakan penelitian dilakukan pencatatan nama-nama siswa yang berjumlah 24 orang sesuai dengan instrumen tes Push $U p$.

\section{Uji Normalitas Tes Push UpSiswa Ekstrakurikuler}

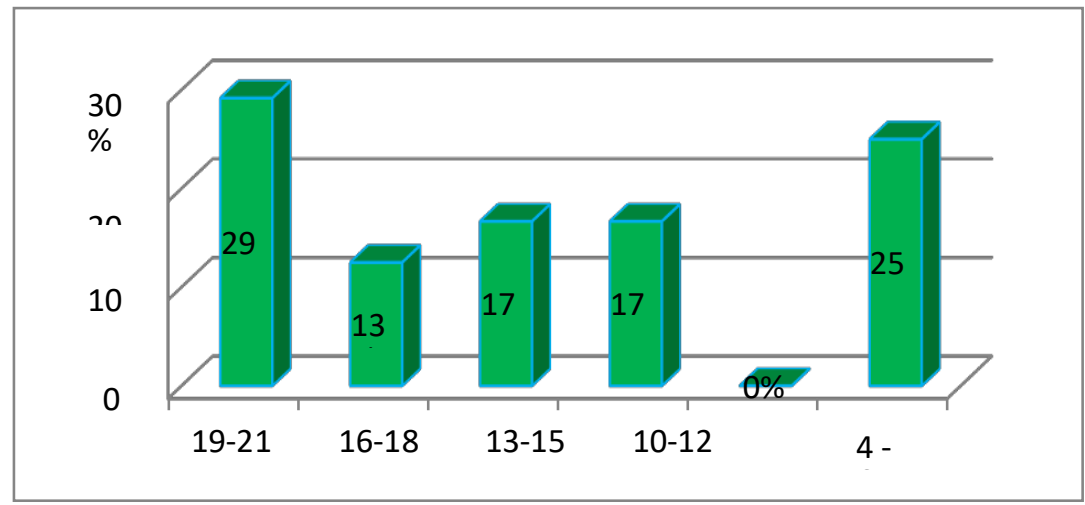

Grafik 1Grafik Kerja Uji Normalitas Data Kekuatan Otot Lengan (Push Up)

Tabel 2

Kerja Uji Normalitas Data Push Up

\begin{tabular}{cccc}
\hline No & Interval & $\begin{array}{c}\text { Meliputi Frekuensi } \\
\text { Sebesar }\end{array}$ & $\begin{array}{c}\text { Dalam } \\
\text { Persentase }\end{array}$ \\
\hline 1 & $19-21$ & 7 & $29 \%$ \\
\hline 2 & $16-18$ & 3 & $13 \%$ \\
\hline 3 & $13-15$ & 4 & $17 \%$ \\
\hline 4 & $10-12$ & 4 & $17 \%$ \\
\hline 5 & $7-9$ & 0 & $25 \%$ \\
\hline 6 & $4-6$ & 6 & $\mathbf{1 0 0 \%}$ \\
\hline
\end{tabular}

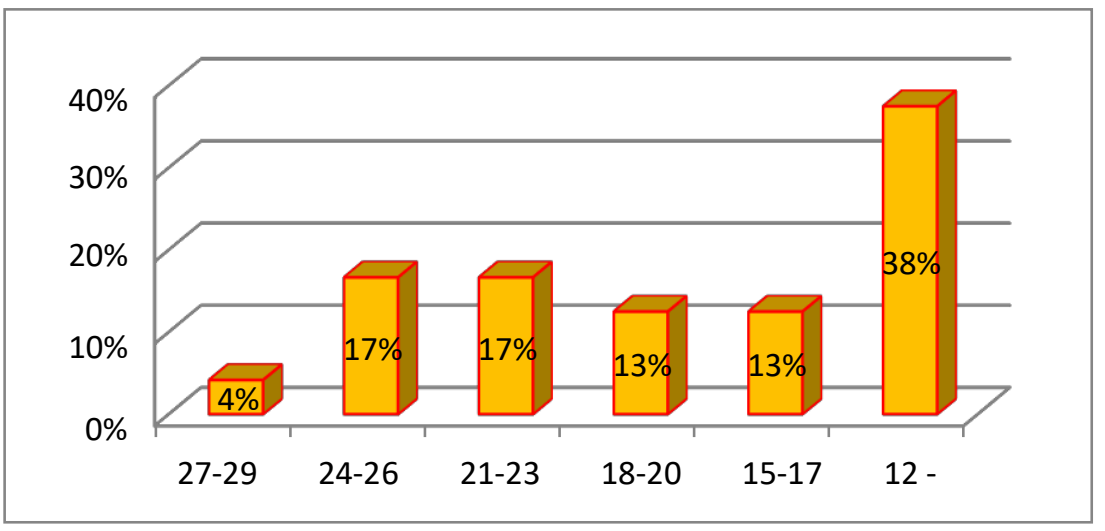

Grafik 2 Kerja Uji Normalitas Data Push Up 
Tabel 3

Kerja Uji Normalitas Data Smash

\begin{tabular}{cccc}
\hline No & Interval & $\begin{array}{c}\text { Meliputi Frekuensi } \\
\text { Sebesar }\end{array}$ & $\begin{array}{c}\text { Dalam } \\
\text { Persentase }\end{array}$ \\
\hline 1 & $27-29$ & 1 & $4 \%$ \\
\hline 2 & $24-26$ & 4 & $17 \%$ \\
\hline 3 & $21-23$ & 4 & $17 \%$ \\
\hline 4 & $18-20$ & 3 & $13 \%$ \\
\hline 5 & $15-17$ & 3 & $13 \%$ \\
\hline 6 & $12-14$ & 9 & $38 \%$ \\
\hline Total & $\mathbf{2 4}$ & $\mathbf{1 0 0 \%}$ \\
\hline
\end{tabular}

\section{PEMBAHASAN}

Berdasarkan hasil tes kekuatan otot lengan (Push Up) pada Siswa Ekstrakurikuler, bahwa kekuatan otot lengan dalam kategori Cukup yaitu dengan rata-rata 13,46. Dan yang memperoleh norma tes di kategori baik sekali sebanyak 7 orang, berkategori baik sebanyak 3 orang, berkategori cukup sebanyak 4 orang, berkategori kurang sebanyak 4 orang dan yang mendapat nilai berkategori sangat kurang sebanyak 6 orang. Nilai tertinggi adalah 21 dan nilai terendah adalah 4.kekuatan otot lengan didapat hasil $\mathrm{X}^{2}$ adalah 7,5 sedangkan $\mathrm{x}^{2}$ tabel 35,415 yang berati ditribusi normal. Sedangkan tingkat keterampilan smash ekstrakurikuler memiliki tingkat keterampilan smash pada kategori baik yaitu dengan rata-rata 18,33 dan yang memperoleh norma tes di kategori baik sekali sebanyak 10 orang, berkategori baik sebanyak 4 orang, berkategori cukup sebanyak 10 orang, berkategori kurang sebanyak 0 orang dan yang mendapat nilai berkategori sangat kurang sebanyak 0 orang. Nilai tertinggi adalah 28 dan nilai terendah adalah 12.kekuatan otot lengan didapat hasil $\mathrm{X}^{2}$ adalah 9 sedangkan $\mathrm{x}^{2}$ tabel 35,415 yang berati ditribusi normal.

Hasil uji homogenitas mendapatkan hasil Fhitung adalah 1,34 dan Ftabel adalah 2,00. Berarti Fhitung 1,34< dari Ftabel 2,00 maka data distribusi homogen. Sedangkan hubungan antara kekuatan otot lengan terhadap keterampilan smash bola voli berdasarkan uji korelasi product moment dengan simpangan antara tes push up dengan keterampilan smash siswa ekstrakurikuler adalah 0,85 pada posisi katagori sangat kuat. Sedangkan nilai ttabel ditentukan berdasarkan tingkat signifikansi $(\alpha)$ adalah 5\% yang digunakan dan derajat kebebasan $($ d.f $=n-2)$ yang besarnya sampel (n) adalah 24, maka d.f $=24-2=22$ berdasarkan distribusi ttabel diperoleh 2,07. Keputusan diambil dengan jalan membandingkan nilai thitung dengan ttabel. Jika thitung lebih kecil dari ttabel, maka keputusan menerima hipotesis Ho. Dan sebaliknya jika thitung lebih besar dari ttabel maka menolak Ho dan menerima Ha, pada pengujian ini, thitung adalah 7,62 lebih besar dari pada ttabel adalah 2,07 maka keputusan menolak hipotesis nol (Ho) dan menerima hipotesis alternatif (Ha). Maka kesimpulannya adalah terdapat korelasi antara variabel $\mathrm{x}$ dan variabel $\mathrm{y}$. Yaitu terdapat hubungan antara kekuatan otot lengan terhadap keterampilan smash bola voli

Kontribusi kekuatan otot lengan terhadap keterampilan smash bola voli adalah sebesar $73 \%$. Dengan ditemukannya kontribusi yang signifikan dari 
kekuatan otot lengan terhadap keterampilan smash bola voli, maka kekuatan otot lengan dapat dijadikan sebagai alat untuk memprediksi keterampilan smash bola voli. Smash adalah suatu tindakan memukul bola dengan keras menggunakan teknik tertentu agar bola bisa memasuki lapangan lawan main dengan harapan tidak bisa dibendung oleh regu lain sebagai lawan dalam permainan, sehingga bisa meraih nilai. Menurut Ahmadi (2007) smash adalah pukulan bola yang keras dari atas ke bawah dan menukik ke dalam lapangan lawan. Smash atau pukulan keras disebut juga spike merupakan bentuk serangan yang paling banyak dipergunakan dalam upaya memperoleh nilai oleh suatu tim. Hasil penelitian membuktikan bahwa terdapat kontribusi kekuatan otot lengan terhadap keterampilan smash bola voli pada Siswa Ekstrakurikuler adalah sebesar 35\%.

\section{SIMPULAN}

Berdasarkan hasil penelitian yang telah diperoleh maka dapat ditarik kesimpulan bahwa tingkat kekuatan otot lengan pada siswa ekstrakurikuler memiliki tingkat kekuatan otot lengan pada kategori cukup yaitu dengan rata-rata 13,46 dan tingkat keterampilan smash siswa ekstrakurikuler memiliki tingkat keterampilan smash pada kategori baik yaitu dengan rata-rata 18,33.

\section{DAFTAR PUSTAKA}

Ahmadi, N. (2007). Panduan Olahraga Bolavoli. Solo: Era Pustaka Utama.

Ahmadi. (2007). Psikologi Sosial. Jakarta : Rineka Cipta

Barabara, V., R, Fergusson, B.,J. (2004). Bolavoli Tingkat Pemula Devisi Buku Sport. Jakarta: PT. Raja Grafindo Persada.

Djoko, P.,I. (2004). Pedoman Praktis Berolahraga Untuk Kebugaran dan Kesehatan. Yokyakarta: ANDI Ofset.

Harsono. (1998). Coaching dan Aspek Psikologi dalam Coaching. Jakarta: Dirjen Dikti.

Kravitz, L. (2001). Panduan Lengkap Bugar Total.. Jakarta: PT. RajagrafindoPersada

Lutan, R. (2000). Dasar-Dasar Kepelatihan. Jakarta: Departemen Pendidikan dan Kebudayaan.

Nurhasan. (2005).Tes dan Pengukuran Pendidikan Olahraga. Fakultas Pendidikan Olahraga dan Kesehatan Universitas Pendidikan Indenesia. Bandung.

Sovensi, E. (2018). Ketepatan Smash Pemain Bolavoli Siswa SMA Ditinjau dari Koordinasi Mata-Tangan dan Extensi Togok. Gelanggang Olahraga: Jurnal Pendidikan Jasmani Dan Olahraga (JPJO), 2(1), 129-139. https://doi.org/https://doi.org/10.31539/jpjo.v2i1.406

Supriyanto, S. (2018). Pengaruh Metode Latihan Plyometric dan Latihan Beban dengan Kecepatan Reaksi terhadap Power Otot Tungkai Pemain Bolavoli Putra. Gelanggang Olahraga: Jurnal Pendidikan Jasmani Dan Olahraga (JPJO), $\quad$ 2(1), 176-189. https://doi.org/https://doi.org/10.31539/jpjo.v2i1.423

Widiastuti. (2017). Tes dan Pengukuran Olahraga. Jakarta: Rajawali Pers.

Wijatmiko, A. (2012). Upaya Peningkatan Pembelajaran Passing Bawah Bolavoli Melalui Pendekatan Bermain Melempar Bola Pada Siswa Kelas IV SD Negeri I Kebokura Kecamatan Sumpiuh Kabupaten Banyumas Tahun 2011/2012. 